\title{
Effects of dietary oxysterols on coronary arteries in hyperlipidaemic hamsters
}

\author{
Alexandra Meynier ${ }^{1}$, Jeanine Lherminier $^{2}$, Joelle Demaison-Meloche ${ }^{1}$, Christian Ginies ${ }^{3}$, \\ Andre Grandgirard ${ }^{1}$ and Luc Demaison ${ }^{1 *}$ \\ INRA, Unité de Nutrition Lipidique, BP 86510, 17 rue Sully, 21065 Dijon, France \\ INRA, Service Commun de Microscopie, BP 86510, Bretenière, 21065 Dijon, France \\ INRA, Laboratoire de Recherche sur les Arômes, BP 86510, 17 rue Sully, 21065 Dijon, France
}

(Received 30 March 2001 - Revised 3 December 2001 - Accepted 21 December 2001)

\begin{abstract}
The aim of this study was to evaluate the effect of dietary oxysterols on coronary atherosclerosis and vasospasm. Golden Syrian hamsters were fed three diets with different lipid contents for 3 months: (1) a normolipidaemic diet containing $25 \mathrm{~g}$ corn oil-fish oil (4:1, w/w) $/ \mathrm{kg}$ (group Low L); (2) a hyperlipidaemic diet composed of the normolipidaemic diet supplemented with $150 \mathrm{~g}$ lard $+30 \mathrm{~g}$ cholesterol/kg (group High L); (3) a third diet, similar to the hyperlipidaemic diet, in which $4 \mathrm{~g}$ cholesterol/kg was replaced by a mixture of oxysterols (group High $\mathrm{L}+\mathrm{OS})$. The oxysterol mixture contained $(\mathrm{g} / \mathrm{kg})$ : 5,6 $\alpha$-epoxycholesterol 211, 5,6 6 -epoxycholesterol 179, $7 \alpha$-hydroxycholesterol $67,7 \beta$-hydroxycholesterol $(7 \beta \mathrm{OH})$ 185, 7-ketocholesterol (7 K) 235; and trace amounts of 7-hydroperoxycholesterols (approximately $30 \mathrm{~g} / \mathrm{kg}$ ). Atherosclerosis was evaluated by measuring myocardial $\mathrm{Ca}$, oxysterols and acyl-CoA cholesterol acyl transferase (ACAT) activity; furthermore, coronary reactivity to sodium nitroprusside $(5 \times$ $10^{-6} \mathrm{M}$ ) was measured and the morphology of coronary arteries was visualized by transmission electron microscopy. Coronary spasm was determined by evaluating reactivity to serotonin $\left(5 \times 10^{-6} \mathrm{M}\right)$. Feeding the high-lipid diet (group High L) increased the plasma level of $7 \beta \mathrm{OH}, 7 \mathrm{~K}$ and cholestanetriol. The presence of oxysterols in the diet (group High L + OS) further increased the concentrations of $7 \beta \mathrm{OH}$ and $7 \mathrm{~K}$ in the plasma. However, as evidenced by myocardial $\mathrm{Ca}$, ACAT activity and coronary reactivity to sodium nitroprusside, severe atherosclerosis did not develop during the 3-month diet. $7 \mathrm{~K}$ was increased in myocardial lipids of groups High L and High L + OS. Electron microscopy did not show the development of atherosclerosis in group High L, whereas vascular wall thickening, endothelial damage and smooth muscle cell proliferation and migration occurred when oxysterols were present in the food. Serotonin $\left(5 \times 10^{-6} \mathrm{M}\right)$ induced exacerbated coronary vasoconstriction in group High $\mathrm{L}$ that was completely reversed by dietary oxysterols. In conclusion, dietary oxysterols exhibit antispasmodic properties, but they cannot be used as agents against excess dietary lipid-induced coronary spasm because of their atherogenic properties.
\end{abstract}

Coronary arteries: Dietary oxysterols: Atherosclerosis: Vasospasm

Cholesterol oxidation products, also called oxysterols (OS), are formed in the diet during the heating (Chien et al. 1998) and storage of cholesterol-rich foods. They are found in noticeable amounts in egg powder, several cheeses, milk powder, lard-fried French fries and other meat-containing dishes (Peng \& Taylor, 1984; RoseSallin et al. 1995; Brown \& Jessup, 1999). Their potential atherogenic properties have been mentioned throughout the last century (Anitschkow, 1913; Imai et al. 1976; Peng et al. 1978 Jacobson, 1987). Dietary OS are absorbed and carried to the organs by LDL and albumin, but they are not only supplied by food. They can also be synthesised in vivo, either by autoxidation or by enzymatic reaction (Smith, 1996). The proportion of OS provided by food as compared with those formed in vivo is difficult to determine. However, the cholesterol oxidation products

Abbreviations: ACAT, acyl-CoA cholesterol acyl transferase; High L, hyperlipidaemic diet; High L + OS, hyperlipidaemic diet + oxysterols; Low L, normalipidaemic diet; OS, oxysterols.

* Corresponding author: Dr Luc Demaison, fax +33 3806332 23, email luc.demaison@dijon.inra.fr 
synthesised in vivo may be responsible for the atherogenic effect of excess dietary cholesterol (Bjorkhem et al. 1991; Hodis et al. 1992; Inouye et al. 1998). In the organism, cholesterol is carried to the organ by plasma LDL. LDL can be oxidatively modified in the blood or in contact with the cells (Axelson \& Larsson, 1995; Cader et al. 1997; Dyer et al. 1997), which allows the formation of OS. When in contact with vascular cells, OS exhibit a potent toxic effect, resulting in cell death (Hugues et al. 1994; Colles et al. 1996; Nishio et al. 1996), loss of endothelial permeability (Boissonneault et al. 1991a,b), LDL invasion in the vascular wall and formation of fatty streaks (Campbell \& Campbell, 1997). This initiates the atherosclerotic process. They are thus suspected to initiate atherosclerosis via apoptosis of endothelial cells (Lizard et al. 1996). A high surplus of plasma cholesterol and saturated fatty acids can accelerate the atherogenic process after initiation by dietary or endogenously-synthesised OS. Numerous studies have been carried out to evaluate the effect of dietary OS on atherosclerosis (Brown \& Jessup, 1999). A part of them have concluded that dietary OS are strong atherogenic agents (Imai et al. 1976; Shih, 1980; Staprans et al. 1998). However, several other studies have shown that dietary OS reduce the severity of atherosclerosis induced by excess dietary lipids (Arakami et al. 1967; Tipton et al. 1987). These discrepancies might be due to the type of OS tested and/or the vessel studied. It is not known if the inducers of atherosclerosis are the same in the large vessels (aorta, carotids or femoral arteries) and coronary arteries.

Acute myocardial infarction can also be due to coronary vasospasm (Lip et al. 1998; Canavy et al. 1999). Coronary spasm is responsible for ischaemia, myocardial infarction, arrhythmia and sudden death (Fuertes et al. 1998; Lowe et al. 1998). It can occur in a wide variety of situations (Goldstein et al. 1998; Yoshitomi et al. 1998; Caputo et al. 1999; Jeremias et al. 1999; Kugiyama et al. 1999), including excess physical training, surgical interventions and drug therapies. The reasons for its occurrence remain unclear, but its incidence is far from being negligible. Abnormalities in serotonin metabolism are involved in this pathology (Henry \& Yokoyama, 1980). Since OS modulate the reactivity of aorta to several pharmaceutical agents (Deckert et al. 1997), they could affect the severity of vasospasm.

The aim of the present study was to develop a model of coronary atherosclerosis and to evaluate the effect of dietary sterols (cholesterol and OS) on coronary atherosclerosis and vasospasm. Coronary vessels were chosen as a target for this study, since their obstruction can lead to sudden death. To evaluate the severity of coronary atherosclerosis, several variables were studied. Since we were not able to predict the degree of atherosclerotic development susceptible to occur, several variables characteristic of early and severe atherosclerosis have been chosen. AcylCoA cholesterol acyl transferase (ACAT) activity that is rapidly increased during atherosclerosis (Gillies et al. 1986) and visualization of coronary arteries by transmission electron microscopy have been chosen for evaluation of early atherosclerotic development. Myocardial Ca (Jacobson et al. 1985; Sima et al. 1990) and coronary reactivity to sodium nitroprusside (Hein \& Kuo, 1998) have been used to diagnose severe atherosclerosis. Since serotonin is involved in vasospasm (Henry \& Yokoyama, 1980 ), the severity of coronary spasm was evaluated by infusing this agent $\left(5 \times 10^{-6} \mathrm{M}\right)$ in the isolated heart and by determining the reduction in coronary flow.

\section{Materials and methods}

Animals and diets

The present study was carried out in accordance with the Guide for the Care and Use of Laboratory Animals (US National Institutes of Health, 1985). Sixty weaning male Golden Syrian hamsters of Charles River's breeding were used. Other strains of hamsters more sensitive to atherosclerosis (Nicolosi, 1997; Nicolosi et al. 1997) could have been chosen. As compared with other strains, Charles River's hamsters exhibit a low level of plasma LDL (Trautwein et al. 1993), which explains their low sensitivity to atherosclerosis. The interest in this strain is that if dietary OS are highly atherogenic, they should induce the development of the pathology. Weaning hamsters were chosen for two reasons: (1) coronary atherosclerosis begins early in the life of human subjects (Stary, 1994); (2) adaptation to a semisynthetic diet was easier in young hamsters. The animals were housed in individual cages in controlled animal housing. They were assigned to three groups of similar weight average (43.6 (SEM 0.2) g). The animals were fed ad libitum three diets with different lipid contents for 3 months. The low-lipid diet (Low L) was composed of $(\mathrm{g} / \mathrm{kg})$ : casein 230 , wheat starch 360 , sucrose 285 , cellulose 35 , minerals 50 , vitamins 15 , corn oil - fish oil $(4: 1 \mathrm{w} / \mathrm{w}) 25$. A carbohydrate-rich diet enriched with $n-3$ polyunsaturated fatty acids was given to the control group in order to avoid the development of coronary atherosclerosis (Israel \& Gorlin, 1992). The mineral composition of this diet was the following $(\mathrm{g} / \mathrm{kg} \mathrm{min}$ eral mixture): $\mathrm{KH}_{2} \mathrm{PO}_{4} 250, \mathrm{CaCO}_{3} 200, \mathrm{CaHPO}_{4} 200$, $\mathrm{MgSO}_{4} .7 \mathrm{H}_{2} \mathrm{O} 100, \mathrm{NaCl} 100, \mathrm{MgCO}_{3} 4, \mathrm{MgOH}_{2} .5 \mathrm{H}_{2} \mathrm{O}$ 40, $\mathrm{FeSO}_{4} \cdot 7 \mathrm{H}_{2} \mathrm{O} 10, \mathrm{ZnSO}_{4} \cdot 7 \mathrm{H}_{2} \mathrm{O}$ 6, $\mathrm{MnSO}_{4} \cdot \mathrm{H}_{2} \mathrm{O}$, $\mathrm{CuSO}_{4} .5 \mathrm{H}_{2} \mathrm{O} 1 \cdot 2, \mathrm{AlK}\left(\mathrm{SO}_{4}\right)_{2} .12 \mathrm{H}_{2} \mathrm{O} 0.2, \mathrm{~K}_{2} \mathrm{CrO}_{4} \quad 0 \cdot 1$, $\mathrm{NaF} 0 \cdot 1, \mathrm{NiSO}_{4} \cdot 7 \mathrm{H}_{2} \mathrm{O} \quad 0 \cdot 1, \mathrm{CoSO}_{4} .7 \mathrm{H}_{2} \mathrm{O} 0 \cdot 1, \mathrm{KIO}_{3} 0 \cdot 04$, $\left(\mathrm{NH}_{4}\right)_{6} \mathrm{Mo}_{7} \mathrm{O}_{24} \cdot 4 \mathrm{H}_{2} \mathrm{O} \quad 0.02, \quad \mathrm{NH}_{4} \mathrm{VO}_{3} \quad 0 \cdot 01, \quad \mathrm{Na}_{2} \mathrm{SeO}_{3}$ 0.006 . The vitamin mixture contained $(\mathrm{g} / \mathrm{kg})$ : vitamin $\mathrm{A}$ $1 \cdot 2$, cholecalciferol $0 \cdot 1, \mathrm{~K} 0 \cdot 1$, thiamin hydrochloride $0 \cdot 4$, riboflavin $0 \cdot 4$, nicotinic acid 5 , calcium D-pantothenate 1 , pyridoxine hydrochloride $0 \cdot 6$, D-biotin 1 , folic acid $0 \cdot 1$, cyanocobalamin 3 , choline hydrochloride $0 \cdot 2$, DL-methionine $0 \cdot 2, p$-aminobenzoic acid $0 \cdot 01$, inositol $0 \cdot 02$. The high-lipid diet (High L) was composed of the low-lipid diet supplemented with $150 \mathrm{~g}$ lard $+30 \mathrm{~g}$ cholesterol $/ \mathrm{kg}$. In order to get a significant increase in LDL-cholesterol in the hamsters (near to that observed in human subjects), a high-lipid diet was prepared by modifying the control diet through the supplementation with $150 \mathrm{~g}$ lard (saturated fat) and $30 \mathrm{~g}$ OS-free (checked by chromatography analysis) cholesterol $/ \mathrm{kg}$, which represents a huge amount of cholesterol as compared with usual protocols (Asami et al. 1999). This high-lipid diet was chosen to verify whether excess OS-free cholesterol induces coronary 
atherosclerosis. Saturated fatty acids $(150 \mathrm{~g} / \mathrm{kg})$ were added in this diet, since it is known that these fatty acids aggravate the development of atherosclerosis. Using a similar diet, Sima et al. (1990) induced the occurrence of coronary atherosclerosis, but the purity of cholesterol was not tested in their study. The cholesterol used for the present study was analysed to test its purity. The presence of OS was evaluated with the method described further. The dietary cholesterol was absolutely devoid of any trace of OS. The high-lipid diet enriched with OS (High L + OS) was similar to the High $\mathrm{L}$ diet, except that $4 \mathrm{~g}$ cholesterol $/ \mathrm{kg}$ cholesterol $(0.1 \mathrm{~g} / \mathrm{kg}$ diet $)$ were replaced by a mixture of OS. When expressed as a percentage of the cholesterol level, the dietary supply of OS in human subjects is similar. The mixture of OS was obtained by heating $\left(135^{\circ} \mathrm{C}\right)$ cholesterol dissolved in a lipid matrix (lard) under a carbogen $\left(\mathrm{O}_{2}-\mathrm{CO}_{2}(95: 5, \mathrm{v} / \mathrm{v})\right)$ stream for $48 \mathrm{~h}$. The fatty acids were saponified and the sterol fraction was extracted with dichloromethane and water. Complete extraction was achieved when the $\mathrm{pH}$ of the aqueous phase was neutral. The OS profile of the diet is presented in Fig. 1. As analysed by GC, it contains ( $/ \mathrm{kg}$ total OS): $7 \alpha$-hydroxycholesterol $67,7 \beta$-hydroxycholesterol $185,5,6 \alpha$-epoxycholesterol 211, 5,6ß-epoxycholesterol 176 and 7-ketocholesterol 235. 25-Hydroxycholesterol was not detected. The method used to produce the OS should also promote the formation of 7-hydroperoxycholesterols that could not be detected by GC analysis. To verify if hydroperoxycholesterols were formed during the procedure of OS synthesis, the final mixture was separated by silicagel TLC using a mixture of hexane-tert-butyl methyl ether-methanol-acetic acid (90:20:3:2, by vol.) as an eluant. The separation allowed the detection of seven spots. Each spot was collected and extracted with hexane. The compounds were then silylated and analysed by GC. Each spot was characterized, except the seventh that was not detected in GC. To find out whether this spot contained hydroperoxycholesterols, it was reduced with $\mathrm{NaBH}_{4}$ according to the method of Malavasi et al. (1992). After silylation, the compound detected by GC and MS was $7 \alpha$-hydroxycholesterol. This indicates that the seventh spot was 7-hydroperoxycholesterols. The amount was low (less than $30 \mathrm{~g} / \mathrm{kg}$ total OS). Even with hydroperoxycholesterols, the sum of OS in the mixture is only $900 \mathrm{~g} / \mathrm{kg}$ OS. The remaining products separated by GC were not present in sufficient amount to be recognized and quantified. They probably were other OS. To avoid peroxidation in the diet, the chow was prepared and totally replaced every $2 \mathrm{~d}$. As evaluated by GC, cold storage of the lipid fraction did not promote the formation of OS during the duration of the experiment. Similarly, storage of the diet in the cages at room temperature for $2 \mathrm{~d}$ did not cause the oxidation of cholesterol.

\section{Heart perfusion}

After being fed the diet for 3 months, the hamsters were anaesthetized with sodium pentobarbital $(60 \mathrm{mg} / \mathrm{kg})$ and heparinized (850 IU). Blood samples were collected through the abdominal aorta. The samples were centrifuged $\left(500 \mathrm{~g}, 10 \mathrm{~min}, 4^{\circ} \mathrm{C}\right)$ and the plasma was collected. 2,6-ditert-butyl-4-methylphenol solution $(1 \mathrm{ml} / \mathrm{l}$ ethanol) was added to the plasma samples. After rapid thoracotomy, the heart was removed and immediately placed in a cold Krebs-Heinseleit buffer until cessation of beating. It was perfused isovolumetrically at constant pressure $(60 \mathrm{mmHg})$ according to the Langendorff mode with a Krebs-Heinselet buffer containing (mM): $\mathrm{NaCl} 118, \mathrm{KCl}$ 5.6, $\mathrm{CaCl}_{2} 1 \cdot 9, \mathrm{MgCl}_{2} 1 \cdot 2, \mathrm{NaHCO}_{3} 20, \mathrm{KH}_{2} \mathrm{PO}_{4}$ 2, and glucose 11. During the perfusion period, the heart was electrically paced ( 220 beats $/ \mathrm{min})$. The heart was perfused under basal conditions for $15 \mathrm{~min}$. Thereafter, different pharmaceutical agents (sodium nitroprusside and serotonin) were infused at a rate never exceeding $1 \%$ of the

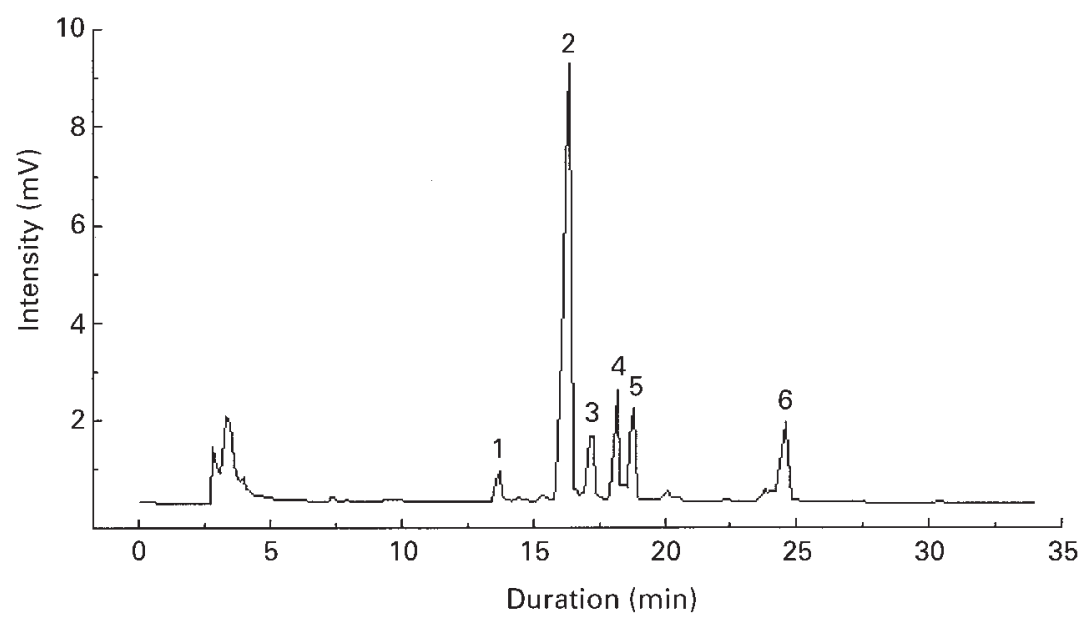

Fig. 1. Oxysterol profile of the hyperlipaemic diet plus oxysterols (High $L+O S$ ). In the other diets (Low $L$ and High $L$ ), no oxysterol was present. For details of diets and procedures, see p. 448. 1,7 $\alpha$-hydroxycholesterol ( $67 \mathrm{~g} / \mathrm{kg}$ total oxysterols); 2,19-hydroxycholesterol (internal standard); 3,7 $\beta$-hydroxycholesterol (185 g/kg total oxysterols); $4,5,6 \beta$-epoxycholesterol (176 g/kg total oxysterols); 5,5,6 $\alpha$-epoxycholesterol $(211 \mathrm{~g} / \mathrm{kg}$ total oxysterols); 6,7-ketocholesterol ( $235 \mathrm{~g} / \mathrm{kg}$ total oxysterols). 
coronary flow. The final concentration of these agents was $5 \times 10^{-6} \mathrm{M}$, since it caused maximal changes in coronary flow without noticeably affecting left-ventricular-developed pressure. These pharmacological solutions were prepared extemporaneously, before each infusion. Throughout perfusion, left-ventricular-developed pressure was recorded with a latex balloon inserted into the left ventricle and connected to a pressure gauge, amplifier and recorder. The coronary flow was evaluated by weight determination of $30 \mathrm{~s}$ samples collected every min. Before the end of the perfusion, a bolus $(0.6 \mathrm{ml})$ of albumin-bound (fatty acid: albumin ratio $0 \cdot 11)\left[1-{ }^{14} \mathrm{C}\right]$ palmitate (palmitate concentration $1.1 \mu \mathrm{M}$, total radioactivity $30 \mathrm{kBq} /$ $\mathrm{ml}$ ) was injected directly into the coronary bed. The heart was then perfused with non-radioactive Krebs-Heinseleit buffer for $2 \mathrm{~min}$. Thereafter, it was freeze-clamped in liquid $\mathrm{N}_{2}$. The heart was stored at $-80^{\circ} \mathrm{C}$ until biochemical analysis (determination of cardiac OS, myocardial $\mathrm{Ca}$ and ACAT activity). Twelve hearts were perfused in each group.

\section{Myocardial calcium}

Each perfused heart was pulverized in liquid $\mathrm{N}_{2}$. A first portion $(100 \mathrm{mg})$ made it possible to determine myocardial dry weight, a second portion $(200 \mathrm{mg}$ ) allowed the evaluation of ACAT activity and a third portion $(150 \mathrm{mg}$ ) was used to quantify myocardial calcium or OS. The assay of cardiac Ca was carried out with six samples of pulverized myocardium in each group. Myocardial $\mathrm{Ca}$ was extracted with perchloric acid (final concentration $0.6 \mathrm{M}$ ). Ca crystals were solubilized by heating the homogenate at $80^{\circ} \mathrm{C}$ for $1 \mathrm{~h}$. After cooling, the homogenate was centrifuged $\left(500 \mathrm{~g}, 20 \mathrm{~min}, 4^{\circ} \mathrm{C}\right)$. Total $\mathrm{Ca}$ was quantified in the supernatant fraction by flame photometry (Elex 6361, Eppendorff, Roucaire, Veluzy, France).

\section{Incorporation of $\left[{ }^{14} \mathrm{C}\right]$ palmitate in cardiac lipids}

The assay was carried out in each perfused heart to estimate the activity of ACAT that allows the incorporation of fatty acids in cholesteryl esters. A portion of the pulverized myocardium (200 mg) was extracted with perchloric acid (final concentration $0 \cdot 6 \mathrm{M}$ ). The homogenate was centrifuged $\left(500 \mathrm{~g}, 20 \mathrm{~min}, 4^{\circ} \mathrm{C}\right)$. The supernatant fraction, containing acid soluble compounds resulting from $\left[{ }^{14} \mathrm{C}\right]$ palmitate $\beta$-oxidation. Its radioactivity was evaluated with a liquid scintillation counter (2000CA Tri-Carb; Packard, Groningen, The Netherlands) with ACS II as a scintillation fluid (Amersham International, Amersham, Bucks., UK). The results were corrected for the quenching activity. The pellet contained total cardiac lipids. They were extracted according to Folch et al. (1957). The radioactivity of the aqueous phase was determined. It contained radioactive amphiphile molecules such as palmitoylcarnitine and palmitoylCoA. The lipid phase was evaporated and the lipids were dissolved with $1 \mathrm{ml}$ chloroform-methanol $(1: 1, \mathrm{v} / \mathrm{v})$. Total lipid radioactivity was quantified in an aliquot $(200 \mu \mathrm{l})$. Myocardial incorporation of $\left[{ }^{14} \mathrm{C}\right]$ palmitate was estimated as the sum of the radioactivity of different extraction compartments (acid-soluble, aqueous and lipid phases). The remaining lipid extract was used to separate the different lipid classes by TLC (Brown \& Johnston, 1962). Elution was carried out with hexanetert-butyl methyl ether-methanol-acetic acid (90:20:3:2, by vol.). Polar lipids, diacylglycerol, free fatty acids, triacylglycerol and cholesteryl esters were detected with pure standards. The radioactivity of each lipid class was determined with a radioscanner (Berthold, La Queue-Lez-Yvelines, France). ACAT activity was estimated as the radioactivity incorporated in the cholesterol ester fraction divided by the myocardial incorporation of $\left[{ }^{14} \mathrm{C}\right]$ palmitate.

\section{Quantification of cholesterol and oxysterols}

Total lipids were extracted from each plasma sample according to Moilanen \& Nikkari (1981). In order to determine cardiac sterols, the frozen powder of six hearts was randomly selected from each group. Two were pooled for each assay, because of the small size of the heart (approximately $0.5 \mathrm{~g}$ wet weight) and need of other biochemical analysis. Their lipids were extracted according to Folch et al. (1957) with chloroform-methanol (2:1, v/v). 19-Hydroxycholesterol was added as an internal standard. Lipids were saponified with $2 \mathrm{M}-\mathrm{KOH}$ in methanol over night at room temperature. The unsaponified fraction was extracted with tert-butyl methyl ester. For the plasma, an aliquot of the unsaponified fraction was transformed into trimethylsilyl ethers and injected into a GC to quantify the cholesterol. OS were purified on silica cartridges (LC-Si SPE 3 ml; Supelco, Sigma Aldrich, L'Isle d'Abeau Chesnes, France) according to the method of Lai et al. (1995) modified as follows: cholesterol and other contaminants were eliminated using $35 \mathrm{ml}$ hexane-tert-butyl methyl ester $(90: 10, \mathrm{v} / \mathrm{v})$ and $15 \mathrm{ml}$ hexane-tert-butyl methyl ester $(80: 20, \mathrm{v} / \mathrm{v})$. OS were then recovered using $5 \mathrm{ml}$ acetone. After the evaporation of acetone, the samples were transformed into trimethylsilyl derivatives with pyridine and $N, O$, bis(trimethylsilyl)trifluoroacetamide-trimethyl chlorosilane $(99: 1, \mathrm{v} / \mathrm{v})$ at $60^{\circ} \mathrm{C}$ for $30 \mathrm{~min}$. Volatiles were evaporated under $\mathrm{N}_{2}$ and the residue was dissolved in hexane and analysed by GC. The OS were injected with a solvent-venting injector. The column was $30 \mathrm{~m}$ long. Its i.d. was $0.32 \mathrm{~mm}$ and it was filled with DB5 $(0.25 \mu \mathrm{m} ; \mathrm{J}$ and $\mathrm{W}$, Folsom, CA, USA). He was used as a vector gas at a pressure of $80 \mathrm{kPa}$. The temperature of the injector and detector was $290^{\circ} \mathrm{C}$. Sterol separation was carried out isothermally at $275^{\circ} \mathrm{C}$. The sensibility of the method was high ( $1 \mathrm{ng}$ OS per peak). The structure of the compounds was checked by GC-MS using a Hewlett-Packard (Palo Alto, CA, USA) 5970 mass selective detector. A $30 \mathrm{~m} \times 0.25 \mathrm{~mm}$ i.d. HP-5 column was used. The MS was operated at ionization energy of $70 \mathrm{eV}$. Mass spectra were recorded between 100 and 700 amu. Using a cholesterol-rich sample devoid of OS, we verified that OS were not produced from cholesterol during the analytical procedure.

\section{Transmission electron microscopy}

Because of the repeatability of the results, only three hamsters were selected randomly from each dietary group. 
After anaesthesia and heparinization, the hearts were immediately perfused according to the Langendorff method at a pressure of $100 \mathrm{mmHg}$ with sodium cacodylate buffer (100 mM, pH 7.4) containing glutaraldehyde (25 g/l). Pieces of myocardium including the main coronary artery were dissected in the fixative solution ( $25 \mathrm{~g}$ glutaraldehyde/l $100 \mathrm{~mm}$-cacodylate buffer, $\mathrm{pH} 7.4$ ) and the sample was fixed for $4 \mathrm{~h}$ at $4^{\circ} \mathrm{C}$. After rinsing in the same buffer, samples were post-fixed in $10 \mathrm{~g}$ osmium tetroxide/l $100 \mathrm{~mm}$-cacodylate buffer $(\mathrm{pH} 7 \cdot 4)$ for $1 \mathrm{~h}$ at $4^{\circ} \mathrm{C}$. They were then dehydrated in an ethanol series (up to $100 \%$ ) followed by propylene oxide and embedded in Epon (Touzart et Matignon, Couretaboeuf, France). Sections were cut on an Ultracut E ultramicrotome (Reichert, Vienna, Austria). Thin sections were collected on $\mathrm{Cu}$ grids and subsequently stained with uranyl acetate (25 g/l) for $20 \mathrm{~min}$ followed by lead citrate for $10 \mathrm{~min}$. Sections were examined with a Hitachi H600 (Hitachio, Tokyo, Japan) electron microscope operating at $75 \mathrm{kV}$. In each heart, fifteen sections obtained at different levels in the middle portion of the right coronary artery were observed by transmission electron microscopy to visualize the greatest portion of artery.

\section{Statistical analysis}

The results are presented as mean values with their standard errors. The data were submitted to one-way ANOVA (Dagnelie, 1975) describing the effect of the diet (Def). Since the normolipaemic and hyperlipaemic diets differed by two factors (type of fatty acids and amount of lipids), the effect of hyperlipidaemia was not treated statistically. The only statistical analysis performed was carried out between groups High L and High L + OS, which describes the effect of dietary OS. A $P$ value $<0.05$ was considered to be statistically significant. All the calculations were performed with NCSS 6.01 software (Alsyd, Meylan, France).

\section{Results}

\section{General results}

At the beginning of the diet, the animals' weights were similar in the three dietary groups (43.5 (SEM 0.4) g). From the second month of diet, the animals fed lard + cholesterol and lard + cholesterol + OS had a lower body weight than control animals $(-22 \%)$. This difference was amplified at the third month of diet $(-27 \%)$. Despite this difference, the animals looked healthy as shown by the appearance of the coat and interest in the surroundings. No significant body weight difference was noticed between groups High L and High L + OS. The dry weight of the hearts of group Low L was higher than that of group High L $(+25 \%)$. That of group High $\mathrm{L}+\mathrm{OS}$ ranged between those of the two other groups, but it was not significantly different.

\section{Plasma level of oxycholesterols}

Plasma levels of cholesterol and oxidized sterols were quantified in the three dietary groups at the end of the feeding period (Table 1). The cholesterol level was increased with the high-lipid diets $(+295$ and $+263 \%$ for the groups High L and High $\mathrm{L}+\mathrm{OS}$ respectively). The presence of OS in the diet did not contribute to reducing the plasma cholesterol level. The amounts of plasma OS were also affected by the diet. In group Low L, the amount of total OS was low (2.38 (SEM 0.38) $\mu \mathrm{g} / \mathrm{ml})$. The most abundant was $4 \beta$-hydroxycholesterol $(520 \mathrm{~g} / \mathrm{kg}$ of total OS). This compound is often difficult to separate from 5,6 $\beta$-epoxycholesterol in GC analysis. However, in our conditions, it was well separated and its structure was checked by MS and compared with an authentic standard. Although missing in the diet, cholestanetriol was present in noticeable amount $(200 \mathrm{~g} / \mathrm{kg}$ total oxysterols). 24-Hydroxycholesterol, 25-hydroxycholesterol and 27-hydroxycholesterol were present in too low an amount to be quantified with precision. The plasma concentration of $7 \alpha$-hydroxycholesterol, 7-ketocholesterol and 7 $\beta$-hydro-

Table 1. The effect of dietary oxysterols on plasma concentrations of cholesterol and oxysterols $(\mu \mathrm{g} / \mathrm{ml})^{\star}$

(Mean values with their standard errors for five hamsters per group)

\begin{tabular}{|c|c|c|c|c|c|c|c|}
\hline \multirow[t]{2}{*}{ Diet... } & \multicolumn{2}{|c|}{ Low L } & \multicolumn{2}{|c|}{ High L } & \multicolumn{2}{|c|}{ High L + OS } & \multirow{2}{*}{$\begin{array}{l}\text { Statistical significance } \\
\text { of effect (ANOVA): P† }\end{array}$} \\
\hline & Mean & SEM & Mean & SEM & Mean & SEM & \\
\hline $\mathrm{Ch}$ & 1131 & 63 & 4438 & 204 & 4082 & 209 & NS \\
\hline $4 \beta-O H$ & $1 \cdot 2$ & 0.4 & 1.6 & 0.6 & $1 \cdot 2$ & 0.5 & NS \\
\hline $7 \alpha-\mathrm{OH}$ & 0.3 & 0.1 & 0.6 & 0.2 & 0.7 & 0.2 & NS \\
\hline $7 \beta-\mathrm{OH}$ & 0.1 & 0.1 & $0.4^{a}$ & 0.1 & $0.8^{\mathrm{b}}$ & 0.1 & $<0.01$ \\
\hline CT & 0.5 & 0.1 & 1.0 & 0.3 & 1.4 & 0.2 & NS \\
\hline $7 \mathrm{~K}$ & 0.3 & $0 \cdot 1$ & $0.6^{\mathrm{a}}$ & $0 \cdot 1$ & $0 \cdot 8^{b}$ & $0 \cdot 1$ & $<0.05$ \\
\hline
\end{tabular}

Low L, normolipidaemic diet; High L, hyperlipidaemic diet; High L + OS, hyperlipidaemic diet containing a mixture of oxysterols; Ch, cholesterol; $4 \beta-\mathrm{OH}, 4 \beta$-hydroxycholesterol; $7 \alpha-\mathrm{OH}, 7 \alpha$-hydroxycholesterol; $7 \beta-\mathrm{OH}, 7 \beta$-hydroxycholesterol; $\mathrm{CT}$, cholestanetriol; 7K, 7-ketocholesterol.

${ }^{a, b}$ Mean values within a row with unlike superscript letters were significantly different $(P<0.05)$

${ }^{*}$ For details of diets and procedures, see p. 448.

† Since the low-lipid diet differed from the high-lipid diets by the type and amount of lipids, the statistical analysis was performed only between groups High $L$ and High $L+O S$. 
xycholesterol was low $(120,110$ and $40 \mathrm{~g} / \mathrm{kg}$ total OS respectively). $4 \beta$-Hydroxycholesterol and $7 \alpha$-hydroxycholesterol were not affected by the diet. Conversely, cholestanetriol, 7-ketocholesterol and 7 $\beta$-hydroxycholesterol were increased by the high-lipid diets $(+144,+144$ and $+525 \%$ respectively). The presence of OS in the diet contributed to increasing the amounts of 7-ketocholesterol and $7 \beta$-hydroxycholesterol in the plasma $(+32$ and $+84 \%$ in group High L + OS as compared with group High L respectively).

\section{Development of coronary atherosclerosis}

Cardiac functioning was evaluated during perfusion according to the Langendorff method. Basal coronary flow (53 (SEM 4), 65 (SEM 5) and 59 (SEM 3) $\mathrm{ml} / \mathrm{min}$ per g dry weight for groups Low L, High L and High $\mathrm{L}+$ OS respectively) and left ventricular developed pressure (42 (SEM 6), 49 (SEM 6) and 47 (SEM 6) mmHg for groups Low L, High L and High L + OS respectively) were not significantly affected by the diet. The incorporation of $\left[1-{ }^{14} \mathrm{C}\right]$ palmitate into cardiac lipids was investigated during the perfusion procedure. Myocardial incorporation of palmitate was not affected by the diet (2.07 (SEM 0.31), 2.55 (SEM 0.23) and 2.48 (SEM 0.22) nmol palmitate equivalent/g dry weight for groups Low L, High L and High L + OS respectively; NS). In the myocardium, palmitate was preferentially incorporated in the lipid phase (approximately 1.58 (SEM 0.18 ) nmol palmitate equivalent/g dry weight) and its $\beta$-oxidation (radioactivity incorporated in the acid-soluble phase) was less important (0.72 (SEM 0.09) nmol palmitate equivalent/g dry weight). It was poorly incorporated in the aqueous phase (palmitoylcarnitine and palmitoylCoA) of the Folch extraction (0.07 (SEM 0.01) nmol palmitate equivalent/g dry weight). Palmitate incorporation in the acid-soluble, lipid and aqueous phases was not altered by the diet. More than $60 \%$ of the palmitate incorporated into cardiac lipids was found in polar lipids. Palmitate incorporation in diacylglycerol and triacylglycerol was similar (approximately $15 \%$ of the palmitate incorporated into cardiac lipids), but it was low in cholesteryl esters ( $4 \%$ of the palmitate incorporated into cardiac lipids). The diet did not alter ACAT activity as estimated as the amount of palmitate incorporated in cholesteryl esters (0.025 (SEM 0.003), 0.022 (SEM 0.003) and 0.026 (SEM 0.006) nmol palmitate equivalent for groups Low L, High L and High L + OS respectively; NS).

The sterol contents of the myocardium were also quantified (Table 2). In group Low L, the main OS were 5,63epoxycholesterol, 7 $\beta$-hydroxycholesterol, cholestanetriol and 5,6 $\alpha$-epoxycholesterol $(290,190,180$ and $170 \mathrm{~g} / \mathrm{kg}$ total OS respectively). 7-Ketocholesterol and $7 \alpha$-hydroxycholesterol were present in smaller amounts (90 and $80 \mathrm{~g}$ / $\mathrm{kg}$ total OS respectively). The high-lipid diets did not modify 7-hydroxycholesterols, epoxycholesterols and cholestanetriol, but 7-ketocholesterol was similarly increased $(+82 \%)$ in groups High L and High L + OS. The cholesterol content was higher $(+38 \%)$ in groups High L and High L + OS than in group Low L.

The influence of the diet on the morphology of coronary arteries was evaluated by transmission electron microscopy. In group Low L (Fig. 2(A) and (B), endothelial cells were smooth and the basal lamina was thin and constant. Moreover, several layers of smooth muscle cells were perfectly organized. In group High L (Fig. 2(C) and (D), the majority of coronary wall was healthy, but some zones were different. In these last zones, the endothelial cells appeared to be healthy whereas the smooth muscle cells were scarce and stretched out. There was no sign of atherosclerosis. On the contrary, in group High L + OS (Fig. 2(E) and (F), the luminal surface of the endothelial cells was scalloped in numerous zones. Some of the smooth muscle cells migrated into the lamina and probably modified their phenotype. The basal lamina appeared to be thick and was located between phenotypically modified and contractile smooth muscle cells. This morphology indicated the development of atherosclerosis. Although the results of electron microscopy are difficult to quantify, the repeatability of the observations at different levels in the coronary vessel of each heart and in each dietary groups suggests that the given conclusions are reliable.

The myocardial $\mathrm{Ca}$ concentration was quantified by flame photometry. The amount of $\mathrm{Ca}$ was small and not affected by the diet. Furthermore, coronary reactivity to

Table 2. The effect of dietary oxysterols on cardiac concentrations of the different sterols $\left(\mu \mathrm{g} / \mathrm{g}\right.$ mycardium) ${ }^{\star}$ (Mean values and their standard errors for three hamsters per group)

\begin{tabular}{|c|c|c|c|c|c|c|c|}
\hline \multirow[t]{2}{*}{ Diet... } & \multicolumn{2}{|c|}{ Low L } & \multicolumn{2}{|c|}{ High L } & \multicolumn{2}{|c|}{ High L + OS } & \multirow{2}{*}{$\begin{array}{l}\text { Statistical significance } \\
\text { of effect (ANOVA): P† }\end{array}$} \\
\hline & Mean & SEM & Mean & SEM & Mean & SEM & \\
\hline $\mathrm{Ch}$ & 805 & 93 & 1111 & 145 & 1104 & 118 & NS \\
\hline $7 \alpha-\mathrm{OH}$ & 21 & 9 & 22 & 12 & 28 & 18 & NS \\
\hline $7 \beta-\mathrm{OH}$ & 50 & 21 & 21 & 12 & 55 & 29 & NS \\
\hline$\alpha$-EC & 46 & 33 & 82 & 22 & 73 & 11 & NS \\
\hline$\beta-E C$ & 78 & 58 & 67 & 13 & 73 & 24 & NS \\
\hline CT & 48 & 27 & 53 & 22 & 72 & 24 & NS \\
\hline $7 \mathrm{~K}$ & 24 & 7 & 42 & 4 & 44 & 4 & NS \\
\hline
\end{tabular}

Low L, normolipidaemic diet; High L, hyperlipidaemic diet; High L + OS, hyperlipidaemic diet containing a mixture of oxysterols; $\mathrm{Ch}$, cholesterol; $7 \alpha-\mathrm{OH}, 7 \alpha$-hydroxycholesterol; $7 \beta-\mathrm{OH}, 7 \beta$-hydroxycholesterol; $\alpha$-EC, 5,6 $\alpha$-epoxycholesterol; $\beta$-EC, 5,6 $\beta$ epoxycholesterol; CT, cholestanetriol; $7 \mathrm{~K}, 7$-ketocholesterol.

${ }^{*}$ For details of diets and procedures, see p. 448.

† Since the low-lipid diet differed from the high-lipid diets by the type and amount of lipids, the statistical analysis was performed only between groups High L and High L + OS. 

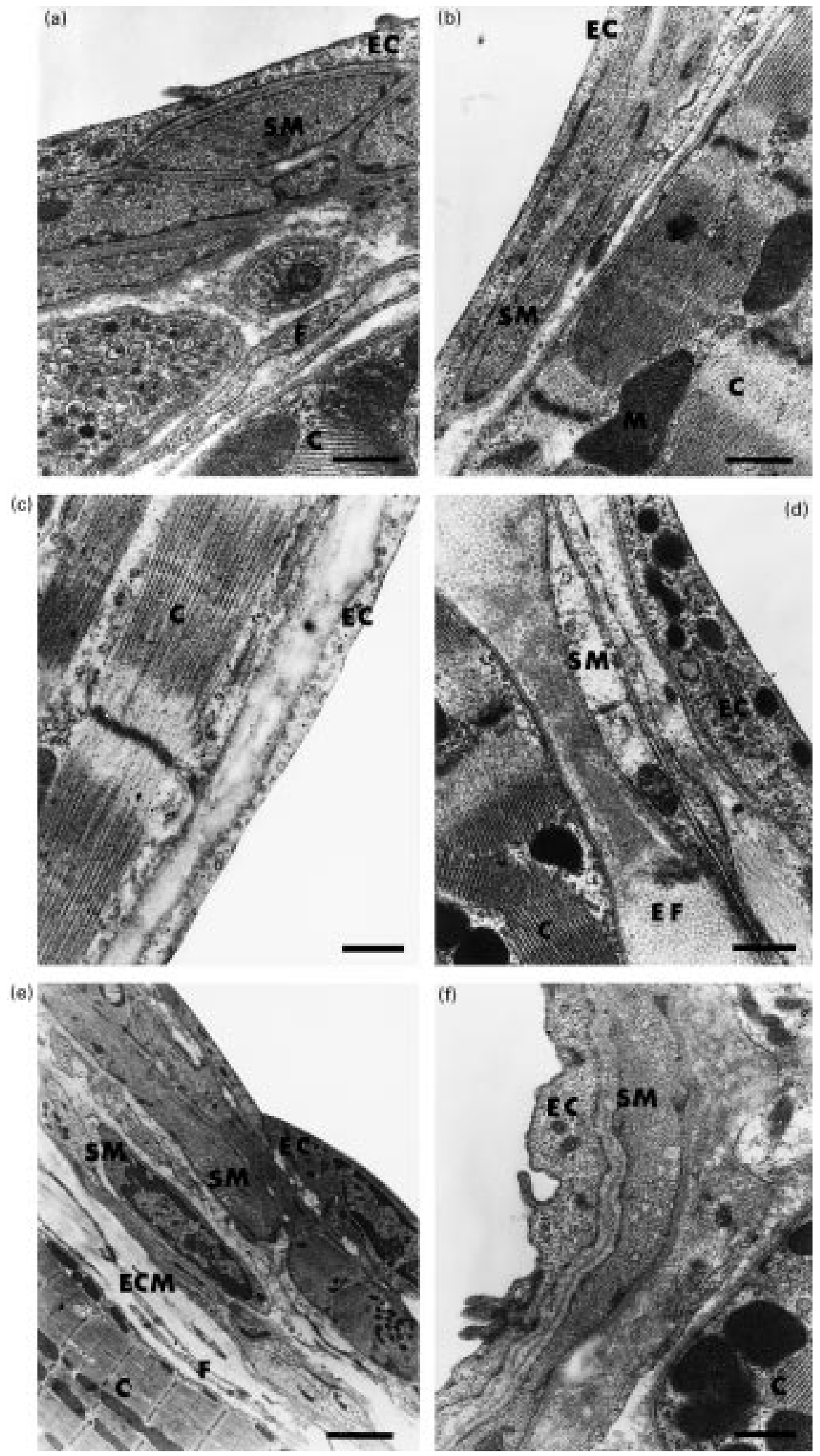

Fig. 2. Influence of dietary oxysterols on the morphology of coronary arteries under normolipidaemic conditions. a,b, coronary artery of hamsters fed a normolipaemic diet (Low L), bars $=0.5 \mu \mathrm{m} ; \mathrm{c}, \mathrm{d}$, coronary artery of hamsters fed a hyperlipaemic diet (High L) $(\mathrm{c}$, bar $=0.4 \mu \mathrm{m}, \mathrm{d}$, bar $=0.5 \mu \mathrm{m}$; e,f, coronary artery of hamsters fed a hyperlipaemic diet plus oxysterols (High $L+O S),(E, b a r=2 \mu m, F, b a r=0.5 \mu m$. EC, endothelial cell; SM, smooth muscle cell; F, fibroblast; M, mitochondria; C, cardiomyocyte; ECM, extracellular matrix; EF, elastic fibres. For details of diets and procedures, see p. 448. 
sodium nitroprusside $\left(5 \times 10^{-6} \mathrm{M}\right)$ was evaluated in the three dietary groups. Sodium nitroprusside induced a rapid increase in coronary flow that remained high thereafter. This increase averaged 57 (SEM 3) \% of the basal coronary flow. It was associated with a slight enhancement of left-ventricular-developed pressure $(+13 \%$ of basal leftventricular-developed pressure) that was similar in the three dietary groups. Sodium nitroprusside-induced vasodilatation was not affected by the diet.
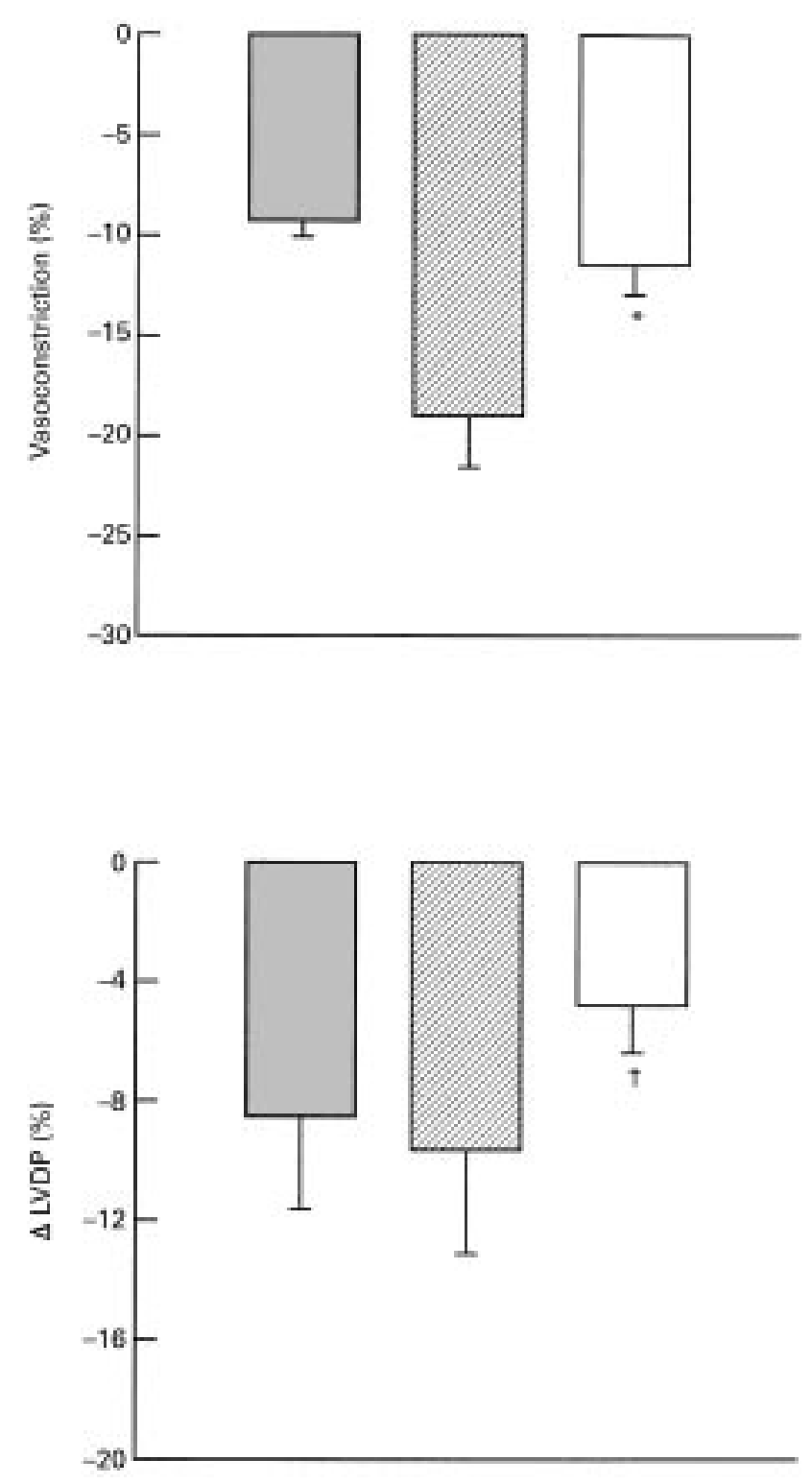

Fig. 3. Influence of the different diets on vasoconstriction induced by serotonin $\left(5 \times 10^{-6} \mathrm{M}\right)$. $\square$, normolipaemic diet (Low L); 四, hyperlipaemic diet (High L); $\square$, hyperlipaemic diet plus oxysterols (High $\mathrm{L}+\mathrm{OS}$ ). $\Delta \mathrm{LVDP}$, variation in left-ventricular-developed pressure. For details of diets and procedures, see p. 448. Values are means for eleven experiments per group with standard errors shown by vertical bars. Since the low-lipid diet differed from the high lipid diets by the type and amount of lipids, the statistical analysis was performed only between groups High $\mathrm{L}$ and High $\mathrm{L}+\mathrm{OS}$. Mean value was significantly different from that of High $L$ group: ${ }^{*} P<0.05$. Mean value was not significantly different from that of the High $L$ group: $\dagger P>0.05$.

\section{Coronary spasm}

Serotonin was infused into the coronary bed at the final concentration of $5 \times 10^{-6} \mathrm{M}$ (Fig. 3). It brought about rapid and constant vasoconstriction corresponding to -13 (SEM 1) \% of the basal coronary flow. Left-ventriculardeveloped pressure was also reduced, but to a lesser extent (-8 (SEM 2) \% of basal left-ventricular-developed pressure). Coronary reactivity to serotonin was altered by the diet. The vasoconstrictive effect was twice as marked in group High L than in group Low L. OS feeding prevented the excess serotonin-induced vasoconstriction observed with the high-lipid diet, reducing the value to that observed in group Low L. The decrease in left-ventricular-developed pressure accompanying serotonin-induced vasoconstriction was not changed by the diet.

\section{Discussion}

The aim of the present study was to determine the influence of dietary OS on the cardiovascular system in hyperlipidaemic hamsters, with a particular focus on coronary atherosclerosis and vasospasm. Diets supplemented with $150 \mathrm{~g}$ lard $+30 \mathrm{~g}$ of cholesterol $/ \mathrm{kg}$ were used. These high-lipid diets containing excess cholesterol reduced the body weight of the animals, suggesting a decreased food intake. However, the animals were healthy and the outcome of the experiment was probably not influenced by the weight loss. The high-lipid diets were chosen to mimic conditions where coronary atherosclerosis develops in the hamster (Sima et al. 1990). Diets containing a lower cholesterol level also induce atherosclerosis in the hamster, but this has been observed in large vessels (Rong et al. 1997). Before beginning the study, we hypothesized that the development of atherosclerosis was more resistant in the coronary bed than in the large vessels. These are the reasons why such an excess cholesterol was used. Since the body weight of the animals was decreased by such an excess cholesterol, the animals reached the maximal threshold of ingestion and plasma cholesterol attained a maximum.

\section{Sterols in food, plasma and heart}

OS were incorporated into the diet as a mixture containing $7 \alpha$ - and $7 \beta$-hydroxycholesterol, 5,6 $\alpha$ - and 5,6 6 -epoxycholesterol, 7-ketocholesterol and trace amounts of 7-hydroperoxycholesterols. These OS are those usually found in human nutrition (Peng \& Taylor, 1984). Furthermore, the mixture was given at a dose of $4 \mathrm{~g} / \mathrm{kg}$ total dietary sterols, which corresponds to the amount that can be found in man's food (Brown \& Jessup, 1999). The dietary OS are absorbed (Linseisen \& Wolfram, 1998) in a proportion ranging from 6 to $93 \%$ (Bascoul et al. 1986), but they can also be synthesized in vivo (Axelson \& Larsson, 1995; Cader et al. 1997; Dyer et al. 1997). Using a ${ }^{18} \mathrm{O}$ inhalation technique, Breuer \& Björkhem (1995) ascertained the in vivo formation of numerous OS; only the epoxycholesterols and cholestanetriol were not observed in the present study. However, in other studies, the in vivo formation of these OS was observed (Watabe et al. 1980). In the present 
study, we noticed that the plasma of the Low L group contained some OS. The level of most OS was higher in group High L. The group High L + OS displayed the highest values due to absorption of dietary OS. The level of $7 \alpha-$ hydroxycholesterol and 4 $\beta$-hydroxycholesterol appears to be well regulated. $7 \alpha$-hydroxycholesterol is known to be easily transformed in biliary acids and excreted (Anderson et al. 1972; Souidi et al. 1999). 4 $\beta$-Hydroxycholesterol was first observed by Breuer (1995) in rat liver and human plasma, as well as in oxidized LDL and atheromatous plaque (Breuer et al. 1996). However, its metabolism is not known. In our present study, the plasma level of $4 \beta$-hydrocholesterol is high as compared with that noticed in rat liver and human plasma. This might be a characteristic of the hamster. In a recent work, we have found much more $4 \beta$-hydroxycholesterol in hamster kidney than in rat (A Grandgirard, J Demaison-Meloche, C Alasnier, C Cordelet and L Demaison, unpublished results). Although present in the diet, the epoxycholesterols were not detected at a significant level in the plasma. It is well known that the epoxy-derivatives can be transformed in cholestanetriol in acidic fluid such as stomach secretion (Maerker et al. 1988; Schroepfer, 2000). This synthesis can also be carried out by an hepatic epoxide hydrolase (Watabe et al. 1980; Sevanian \& McLeod, 1986). The other OS such as 27-hydroxycholesterol and 24-hydroxycholesterol were not quantified in the present study, since they were present in a too low dose to be clearly separated from the baseline. In the literature no information is available about the plasma concentration of these two OS in the hamster. However, since they are involved in the elimination of cerebral (Lutjohann et al. 1996) and cellular (Anderson et al. 1972) cholesterol, it seems logical that their plasma concentration is low. Very little information is available on 7-hydroperoxycholesterols: the main methods used to identify and quantify the OS may destroy the hydroperoxysterols and their stability in diet and tissues is not well known. In this experiment, the hydroperoxycholesterols were not detected in plasma and heart.

Hyperlipidaemia (groups High L and High L + OS) triggered 7-ketocholesterol accumulation in myocardial lipids. Dietary 7-ketocholesterol is rapidly excreted (Lyons et al. 1999) via formation of a 27-hydroxylated derivative (Lyons \& Brown, 2001) and does not accumulate in the aorta. However, 7-ketocholesterol accumulation in the vessel wall can result from excess incorporation of cholesterol. Thereafter, cholesterol can be endogenously oxidized in the cell through radical attack and transformed in 7-ketocholesterol. In the present study, myocardial cholesterol was increased by hyperlipidaemia. This was probably responsible for the hyperlipidaemia-induced increase in 7-ketocholesterol. Moreover, 7-ketocholesterol accumulates in both atherosclerotic lesions of the aorta and macrophage foam cells (Lyons et al. 1999; Lyons \& Brown, 2001). We did not observe any relation between 7-ketocholesterol and atherosclerosis, since development of atheroma was noticed in group High L + OS, but not in group High L. These results clearly indicate that vessel accumulation of 7-ketocholesterol is not a marker of atherosclerosis, but rather a sign of excess cholesterol in the cellular compartment that also occurs during atherosclerosis.

\section{Coronary atherosclerosis}

In order to evaluate coronary atherosclerosis, several variables were evaluated. Myocardial OS, Ca, ACAT activity and coronary reactivity to sodium nitroprusside are altered during severe atherosclerosis. Myocardial Ca increases due to Ca deposit in the coronary wall (Sima et al. 1990). ACAT activity can be multiplied by seventy during atherosclerosis (Campbell \& Campbell, 1997), allowing the formation of foam cells and fatty streaks. Similarly, coronary reactivity to sodium nitroprusside is modified only during severe atherosclerosis (Hein \& Kuo, 1998). The fact that these variables were not altered suggests that severe atherosclerosis did not occur in the present study. However, this conclusion must be modulated by the results of coronary electron microscopy. Although we did not develop a method for evaluation of foam cells in the vascular wall, the results obtained by electron microscopy are of great interest. On the one hand, they suggest that atherosclerosis did not occur in group High L. This was surprising, since 3 months of a similar diet induced early coronary atherosclerosis in Golden Syrian hamster (Sima et al. 1990). In this latter study, the cholesterol used may have contained cholesterol oxidation products or the selected strain of animals may have been more sensitive to the development of atherosclerosis. On the other hand, the electron microscopy showed that atherosclerosis developed in group High L + OS, suggesting that the dietary OS exhibited atherogenic properties. OS-induced atherogenicity was high, since the hamster strain used in the present study was not sensitive to atherosclerosis. This effect agrees with a large number of animal studies showing that the dietary supply of OS or the endogenous formation of cholesterol oxidation products is responsible for atherosclerosis (Imai et al. 1976; Shih, 1980; Peng \& Taylor, 1983; Jacobson et al. 1985; Matthias et al. 1987; Mahfouz et al. 1997; Salonen et al. 1997; Staprans et al. 1998; Rong et al. 1998). A recent study (Van Poppel et al. 1997) showed no correlation between circulating OS levels and signs of atherosclerosis. However, OS toxicity is high and rapid (Ramasamy et al. 1992; Hughes et al. 1994; Clare et al. 1995; Lizard et al. 1996). These molecules may act during a short period and be eliminated thereafter, due to intense metabolism and rapid clearance (Breuer \& Bjorkhem, 1995). For Higley et al. (1986), dietary OS do not favour the development of aortic atherosclerosis in the rabbit, but cholesterol does. This might be explained by an intense in vivo cholesterol oxidation in the rabbit and a low one in the hamster where cholesterol is inefficient. Another study (Lyons et al. 1999) showed that dietary 7-ketocholesterol is rapidly eliminated from the organism. On this basis, the authors suggest that dietary OS make little or no contribution to atherogenesis. However, 7-ketocholesterol was the only OS studied. The other dietary OS can behave differently as compared with 7-ketocholesterol. The results of the present study suggests the contrary. Furthermore, an increased plasma $7 \beta$-hydroxycholesterol concentration was observed in a population with a high risk of cardiovascular disease (Zieden et al. 1999). Our current study indicates that the presence of oxidized cholesterol in the plasma is an 
important cause of the development of atherosclerosis. Moreover, the diet contained 7-hydroperoxycholesterols. Although their amount was low, they might contribute to the atherogenicity of the dietary OS mixture. To study the effect of OS included in a normolipidic diet on the development of coronary atherosclerosis would be of great interest. This condition cannot mimic a specific dietary situation, since ingestion of OS is automatically associated with cholesterol absorption. However, some patients develop coronary atherosclerosis without displaying hypercholesterolaemia. This suggests intense endogenous OS formation. The normolipidic diet enriched with OS could mimic this situation. Such an experiment could constitute the subject of a future study.

\section{Coronary spasm}

Another pathology which is important in coronary heart disease is coronary vasospasm. It brings about chest pain, myocardial ischaemia, infarction and even sudden death. It is partly due to abnormalities in serotonin metabolism (Henry \& Yokoyama, 1980). To investigate the effect of dietary OS on coronary spasm, we evaluated serotonininduced reactivity in isolated perfused heart. Serotonin $(5 \times$ $\left.10^{-6} \mathrm{M}\right)$ brought about stable vasoconstriction that averaged $-10 \%$ of basal coronary flow in group Low L. Serotonin-induced vasoconstriction was exacerbated in group High L, suggesting the occurrence of vasospasm due to either excess plasma saturated fatty acids and/or cholesterol. The reasons for this phenomenon are not known, but it has already been demonstrated in hypercholesterolaemic and atherosclerotic monkeys (Heistad et al. 1984). Exposure of smooth muscle cell serotonin receptors might be causal (Yildiz et al. 1998). Interestingly, dietary cholesterol oxidation products totally prevented excess lipid-induced vasospasm. This indicates that dietary OS exhibit anti-vasospasmic properties. Serotonin acts on endothelial cells by stimulating the synthesis of NO and constricting factors such as superoxide anion, thromboxane $\mathrm{A}_{2}$ and prostaglandin $\mathrm{H}_{2}$ (Shimokawa, 1999). Dietary OS could contribute to modifying the equilibrium between the production of the vasodilator NO and that of the constricting factors. The isoform of nitric-oxide synthase present in vascular endothelial cells, eNOS, is activated by excess intracellular Ca (Ungvari et al. 2001) and dietary OS increase intracellular $\mathrm{Ca}$ in cultured endothelial cells (Ramasamy et al. 1992). This could contribute to increasing serotonin-induced NO production. However, the synthesis of constricting factors could be reduced. Our results do not allow the full interpretation of the effect of dietary OS on vasospasm.

\section{Conclusion}

Dietary OS exhibit anti-spasmodic activity. However, they cannot be used against coronary spasm, because of their possible atherogenic properties.

\section{Acknowledgements}

This work was supported by the Etablissement Public
Régional de Bourgogne. We thank the INRA Translation Service for correcting the English version of this manuscript.

\section{References}

Anderson KE, Kok E \& Javitt NB (1972) Bile acid synthesis in man: metabolism of 7-hydroxycholesterol- ${ }^{14} \mathrm{C}$ and 26 -hydroxycholesterol- ${ }^{3}$ H. Journal of Clinical Investigation 51, 112-117.

Anitschkow N (1913) Über die Veränderungen der Kaninchenaorta bei experimenteller Cholesterin-steatose (About changes in canine aorta during cholesterol-induced steatosis). Beiträge zur Pathologischen Anatomie und zur Allgemeinen Pathologie 56, 379-404.

Arakami Y, Kobayashi T, Imai Y, Kikuchi S, Matsukawa T \& Kanazawa K (1967) Biological studies of cholestane$3 \beta, 5 \alpha, 6 \beta$-triol and its derivatives. Part 1 . Hypocholesterolemic effects in rabbits, chickens and rats on atherogenic diet. Journal of Atherosclerosis Research 7, 653-669.

Asami Y, Yamagishi I, Akiyoshi K, Tomoike H, Tsuchida K \& Higuchi S (1999) Inhibitory effect of TS-962 on the formation of early atherosclerotic lesions in high fat-fed hyperlipidaemic hamsters. Atherosclerosis 146, 237-242.

Axelson M \& Larsson O (1995) Low density lipoprotein (LDL) cholesterol is converted to 27-hydroxycholesterol in human fibroblasts - Evidence that 27-hydroxycholesterol can be an important intracellular mediator between LDL and the suppression of cholesterol production. Journal of Biological Chemistry 270, 15102-15110.

Bascoul J, Domergue N, Mourot J, Debry G \& Crastes de Paulet A (1986) Intestinal absorption and fecal excretion of 5,6 $\alpha$ epoxy-5 $\alpha$-cholesta-3 $\beta$-ol by the male Wistar rat. Lipids $\mathbf{2 1}$, $744-747$.

Bjorkhem I, Henriksson-Freyschuss A, Breuer O, Diczfalusy U, Berglund L \& Henriksson P (1991) The antioxidant butylated hydroxytoluene protects against atherosclerosis. Arteriosclerosis and Thrombosis 11, 15-22.

Boissonneault GA, Hennig B \& Ouyang CM (1991a) Oxysterols, cholesterol biosynthesis, and vascular endothelial cell monolayer barrier function. Proceedings of the Society for Experimental Biology and Medicine 196, 338-343.

Boissonneault GA, Hennig B, Wang Y, Ouyang CM, Krahulik K, Cunnup L \& Oeltgen PR (1991b) Effect of oxysterol-enriched low-density lipoprotein on endothelial barrier function in culture - low-density lipoproteins. Annals of Nutrition and Metabolism 35, 226-232.

Breuer O \& Bjorkhem I (1995) Use of an 18-O(2) inhalation technique and mass isotopomer distribution analysis to study oxygenation of cholesterol in rat - Evidence for in vivo formation of 7-oxo, $7 \beta$-hydroxy-, 24-hydroxy-, and 25-hydroxycholesterol. Journal of Biological Chemistry 270, 2027820284.

Breuer O (1995) Identification and quantification of cholest5-ene-3 $\beta, 4 \beta$ diol in rat liver and human plasma. Journal of Lipid Research 36, 2275-2281.

Breuer O, Dzeletovic S, Lund E \& Diczfalusy U (1996) The oxysterols cholest-5-ene-3 $\beta, 4 \alpha$-diol, cholest-5-ene-3 $\beta, 4 \quad \beta$-diol and cholestane- $3 \beta, 5 \alpha, 6 \alpha$-triol are formed during in vitro oxidation of low density lipoprotein, and are present in human atherosclerotic plaque. Biochimica et Biophysica Acta 1302, $145-152$.

Brown JL \& Johnston JM (1962) Radioassay of lipid components separated by thin-layer chromatography. Journal of Lipid Research 4, 480-481.

Brown AJ \& Jessup W (1999) Oxysterols and atherosclerosis. Atherosclerosis 142, 1-28. 
Cader AA, Steinberg FM, Mazzone T \& Chait A (1997) Mechanisms of enhanced macrophage apoE secretion by oxidized LDL. Journal of Lipid Research 38, 981-991.

Campbell JH \& Campbell GR (1997) The cell biology of atherosclerosis - new developments. Australian and New-Zealand Journal of Medicine 27, 497-500.

Canavy I, Dutrillat C, Garcia E, Bonnet JL \& Bory M (1999) Etude prospective sur le mécanisme de l'infarctus du myocarde sans sténose coronaire significative (Prospective study about the mechanism of myocardial infarction without significant coronary stenosis). Archives des Maladies du Cour et des Vaisseaux 92, 225-233.

Caputo M, Nicolini F, Franciosi G \& Gallotti R (1999) Coronary artery spasm after coronary artery bypass grafting. European Journal of Cardio-Thoracic Surgery 15, 545-548.

Chien JT, Wang HC \& Chen BH (1998) Kinetic model of the cholesterol oxidation during heating. Journal of Agriculture and Food Chemistry 46, 2572-2577.

Clare K, Hardwick SJ, Carpenter KLH, Weeratunge N \& Mitchinson MJ (1995) Toxicity of oxysterols to human monocyte-macrophages. Atherosclerosis 118, 67-75.

Colles SM, Irwin KC \& Chisolm GM (1996) Roles of multiple oxidized LDL lipids in cellular injury: Dominance of $7 \beta$ hydroperoxycholesterol. Journal of Lipid Research 37, 2018-2028.

Dagnelie P (1975) Théories et méthodes statistiques (Statistical Theories and Methods). Gembloux: Presse Agronomique de Gembloux.

Deckert V, Persegol L, Viens L, Lizard G, Athias A, Lallemant C, Gambert P \& Lagrost L (1997) Inhibitors of arterial relaxations among components of human oxidized low-density lipoproteins: cholesterol derivatives oxidized in position 7 are potent inhibitors of endothelium-dependant vasodilatation. Circulation 95, 723-731.

Dyer RG, Stewart MW, Mitcheson J, George K, Alberti MM \& Laker MF (1997) 7-Ketocholesterol, a specific indicator of lipoprotein oxidation, and malondialdehyde in non-insulin dependent diabetes and peripheral vascular disease. Clinica Chimica Acta 260, 1-13.

Folch J, Lees M \& Sloane-Stanley GH (1957) A simple method for the isolation and purification of total lipides from animal tissues. Journal of Biological Chemistry 226, 497-509.

Fuertes J, Gallego P, Peinado R \& Merino JL (1998) Implantable cardioverter defibrillator as therapeutic option for sudden cardiac death secondary to severe coronary vasospasm [see comments]. Comment in: International Journal of Cardiology 65, 209-210. International Journal of Cardiology 63, 181-183.

Gillies PJ, Rathgeb KA, Perri MA \& Robinson CS (1986) Regulation of acyl-CoA:cholesterol acyltransferase activity in normal and atherosclerotic rabbit aortas: role of a cholesterol substrate pool. Experiments in Molecular Pathology 44, 329-339.

Goldstein DR, Dobbs T, Krull B \& Plumb VJ (1998) Clenbuterol and anabolic steroids: a previously unreported cause of myocardial infarction with normal coronary arteriograms. South Medical Journal 91, 780-784.

Hein TW \& Kuo L (1998) LDLs impair vasomotor function of the coronary microcirculation: role of superoxide anions. Circulation Research 83, 404-414.

Heistad DD, Armstrong ML, Marcus ML, Piegors DJ \& Mark AL (1984) Augmented responses to vasoconstrictor stimuli in hypercholesterolemic and atherosclerotic monkeys. Circulation Research 54, 711-718.

Henry PD \& Yokoyama M (1980) Supersensitivity of atherosclerotic rabbit aorta to ergonovine. Mediation by a serotonergic mechanism. Journal of Clinical Investigation 66, 306-313.

Higley NA, Beery JT, Taylor SL, Porter JW, Dziuba JA \& Lalich
JJ (1986) Comparative atherogenic effects of cholesterol and cholesterol oxides. Atherosclerosis 62, 91-104.

Hodis HN, Chauhan A, Hashimoto S, Crawford DW \& Sevanian A (1992) Probucol reduces plasma and aortic wall oxysterol levels in cholesterol fed rabbits independently of its plasma cholesterol lowering effect. Atherosclerosis 96, 125-134.

Hughes H, Mathews B, Lenz ML \& Guyton JR (1994) Cytotoxicity of oxidized LDL to porcine aortic smooth muscle cells is associated with the oxysterols 7-ketocholesterol and 7-hydroxycholesterol. Arteriosclerosis and Thrombosis 14, 1177-1185.

Imai H, Werthessen NT, Taylor CB \& Lee KT (1976) Angiotoxicity and arteriosclerosis due to contaminants of USP-grade cholesterol. Archives of Pathology and Laboratory Medicine 100, 565-572.

Inouye M, Hashimoto H, Abo K, Tsuzuki D, Moi T \& Sumino K (1998) The effect of probucol on oxidized cholesterol disposition in hyperlipidaemic patients. Journal of International Medical Research 26, 233-238.

Israel DH \& Gorlin R (1992) Fish oils in the prevention of atherosclerosis. Journal of the American College of Cardiology 19, $174-185$.

Jacobson MS (1987) Cholesterol oxides in Indian ghee: possible cause of unexplained high risk of atherosclerosis in Indian immigrant populations. Lancet 2, 656-658.

Jacobson MS, Price MG, Shamoo AE \& Heald FP (1985) Atherogenesis in White Carneau pigeons effects of low-level cholestane-triol feeding. Atherosclerosis 57, 209-217.

Jeremias A, Kutscher S, Haude M, Heinen D, Baumgart D, Herrmann J \& Erbel R (1999) Chest pain after coronary interventional procedures. Incidence and pathophysiology. Herz 24, $126-131$.

Kugiyama K, Ohgushi M, Motoyama T, Sugiyama S, Soejima H, Matsumura T, Yoshimura M, Ogawa H \& Yasue H (1999) Enhancement of constrictor response of spastic coronary arteries to acetylcholine but not to phenylephrine in patients with coronary spastic angina. Journal of Cardiovascular Pharmacology 33, 414-419.

Lai SM, Gray JI \& Zabik ME (1995) Evaluation of solid phase extraction and gas chromatography for determination of cholesterol oxidation products in spray-dried whole egg. Journal of Agriculture and Food Chemistry 43, 1122-1126.

Linseisen J \& Wolfram G (1998) Absorption of cholesterol oxidation products from ordinary foodstuff in humans. Annals of Nutrition and Metabolism 42, 221-230.

Lip GY, Ray KK \& Shiu MF (1998) Coronary spasm in acute myocardial infarction. Heart 80, 197-199.

Lizard G, Deckert V, Dubrez L, Moisant M, Gambert P \& Lagrost L (1996) Induction of apoptosis in endothelial cells treated with cholesterol oxides. American Journal of Pathology 148, $1625-1638$.

Lowe MD, Stone DL \& Grace AA (1998) Sotalol associated polymorphic ventricular tachycardia and coronary spasm. Heart 79, 518-520.

Lyons MA \& Brown AJ (2001) Metabolism of an oxysterol, 7-ketocholesterol, by sterol 27-hydroxylase in HepG2 cells. Lipids 36, 701-711.

Lyons MA, Samman S, Gatto L \& Brown AJ (1999) Rapid hepatic metabolism of 7-ketocholesterol in vivo: implications for dietary oxysterols. Journal of Lipid Research 40, 1846-1857.

Lutjohann D, Breuer O, Ahlborg G, Nennesmo I, Siden A, Diczfalusy U \& Bjorkhem I (1996) Cholesterol homeostasis in human brain: evidence for an age-dependent flux of $24 \mathrm{~S}$ hydroxycholesterol from the brain into the circulation. Proceedings of the National Academy of Sciences, USA 93, 9799-9804.

Maerker G, Nungesser EH \& Bunick FJ (1988) Reaction of 
cholesterol 5,6-epoxides with simulated gastric juice. Journal of the American Oil Chemists' Society 23, 761-765.

Mahfouz MM, Kawano H \& Kummerow FA (1997) Effect of cholesterol-rich diets with and without added vitamins $\mathrm{E}$ and $\mathrm{C}$ on the severity of atherosclerosis in rabbits. American Journal of Clinical Nutrition 66, 1240-1249.

Malavasi B, Rasetti MF, Roma P, Fogliatto R, Allevi P, Catapano AL \& Galli G (1992) Evidence for the presence of 7-hydroperoxycholest-5-en-3 $\beta$-ol in oxidized human LDL. Chemistry and Physics of Lipids 20, 214.

Matthias D, Becker CH, Godicke W, Schmidt R \& Ponsold K (1987) Action of cholestane-3 $\beta, 5 \alpha, 6 \beta$-triol on rats with particular reference to aorta. Atherosclerosis 63, 115-124.

Moilanen T \& Nikkari T (1981) The effect of storage on the fatty acid composition of human serum. Clinica Chimica Acta 114, $111-116$.

Nicolosi RJ (1997) Dietary fat saturation effects on low-densitylipoprotein concentrations and metabolism in various animal models. American Journal of Clinical Nutrition $\mathbf{6 5}$, $1617 \mathrm{~S}-1627 \mathrm{~S}$.

Nicolosi RJ, Rogers EJ, Kritchevsky D, Scimeca JA \& Huth PJ (1997) Dietary conjugated linoleic acid reduces plasma lipoproteins and early aortic atherosclerosis in hypercholesterolemic hamsters. Artery 22, 266-277.

Nishio E, Arimura S \& Watanabe Y (1996) Oxidized LDL induces apoptosis in cultured smooth muscle cells: A possible role for 7-ketocholesterol. Biochemical Biophysical Research Communication 223, 413-418.

Peng SK \& Taylor CB (1983) Dietary Fats and Health. Atherogenic effect of oxidized cholesterol. 919-933.

Peng SK \& Taylor CB (1984) Cholesterol autoxidation, health and arteriosclerosis. World Review of Nutrition and Dietetics 44, 117-154.

Peng SK, Taylor CB, Tham P, Werthessen NT \& Mikkelson B (1978) Effect of auto-oxidation products from cholesterol on aortic smooth muscle cells An in vitro study. Archives of Pathology and Laboratory Medicine 102, 57-61.

Ramasamy S, Boissonneault GA \& Hennig B (1992) Oxysterolinduced endothelial cell dysfunction in culture. Journal of the American College of Nutrition 11, 532-538.

Rong N, Ausman LM \& Nicolosi RJ (1997) Oryzanol decreases cholesterol absorption and aortic fatty streaks in hamsters. Lipids 32, 303-309.

Rong JX, Rangaswamy S, Shen LJ, Dave R, Chang YH, Peterson H, Hodis HN, Chisolm GM \& Sevanian A (1998) Arterial injury by cholesterol oxidation products causes endothelial dysfunction and arterial wall cholesterol accumulation. Arteriosclerosis Thrombosis and Vascular Biology 18, 1885-1894.

Rose-Sallin C, Huggett AC, Bosset JO, Tabacchi R \& Fay LB (1995) Quantification of cholesterol oxidation products in milk powders using $[2 \mathrm{H}(7)]$ cholesterol to monitor cholesterol autoxidation artifacts. Journal of Agriculture and Food Chemistry 43, 935-941.

Salonen JT, Nyyssonen K, Salonen R, Porkkala-Sarataho E, Tuomainen TP, Diczfalusy U \& Bjorkhem I (1997) Lipoprotein oxidation and progression of carotid atherosclerosis. Circulation 95, 840-845.

Schroepfer GJ (2000) Oxysterols: Modulators of cholesterol metabolism and other processes. Physiological Reviews 80, $361-554$
Sevanian A \& McLeod LL (1986) Catalytic properties and inhibition of hepatic cholesterol-epoxide hydrolase. Journal of Biological Chemistry 261, 54-59.

Shih JCH (1980) Increased atherogenicity of oxidized cholesterol. Federation Proceedings 39, 650.

Shimokawa H (1999) Primary endothelial dysfunction: atherosclerosis. Journal of Molecular and Cellular Cardiology 31, 23-37.

Sima A, Bulla A \& Simionescu N (1990) Experimental obstructive coronary atherosclerosis in the hyperlipidaemic hamster. Journal of Submicroscopic Cytology and Pathology 22, 1-16.

Smith LL (1996) Review of progress in sterol oxidations: 19871995. Lipids 31, 453-487.

Souidi M, Parquet M, Ferezou J \& Lutton C (1999) Modulation of cholesterol $7 \alpha$-hydroxylase and sterol 27-hydroxylase activities by steroids and physiological conditions in hamster. Life Science 64, 1585-1593.

Staprans I, Pan XM, Rapp JH \& Feingold KR (1998) Oxidized cholesterol in the diet accelerates the development of aortic atherosclerosis in cholesterol-fed rabbits. Arteriosclerosis Thrombosis and Vascular Biology 18, 977-983.

Stary HC (1994) Changes in components and structure of atherosclerotic lesions developing from childhood to middle age in coronary arteries. Basic Research in Cardiology 89, 17-32.

Tipton CL, Leung PC, Johnson JS, Brooks RJ \& Beitz DC (1987) Cholesterol hydroperoxides inhibit calmodulin and suppress atherogenesis in rabbits. Biochemical Biophysical Research Communications 146, 1166-1172.

Trautwein EA, Liang J \& Hayes KC (1993) Cholesterol gallstone induction in hamsters reflects strain differences in plasma lipoproteins and bile acid profile. Lipids 28, 305-312.

Ungvari Z, Sun D, Huang A, Kaley G \& Koller A (2001) Role of endothelial $[\mathrm{Ca} 2+]$ in activation of eNOS in pressurized arterioles by agonists and wall shear stress. American Journal of Physiology 281, H606-H612.

US National Institutes of Health (1985) Laboratory animal welfare: Public Health Service policy on humane care and use of laboratory animals by awardee institutions; notice. Federal Register 50, 19584-19585.

Van Poppel G, Van de Vijver LPL, Kosmeyer-Schuil T, Johanns ESD, Kardinaal AFM, Van de Bovenkamp P, Kruyssen DACM \& Kok FJ (1997) Plasma oxysterols and angiographically determined coronary atherosclerosis: a case-control study. Biomarkers 2, 373-378.

Watabe T, Kanai M, Isobe M \& Ozawa N (1980) Cholesterol $\alpha$ and $\beta$-epoxides as obligatory intermediates in the hepatic microsomal metabolism of cholesterol to cholestanetriol. Biochimica et Biophysica Acta 619, 414-419.

Yoshitomi Y, Kojima S, Sugi T, Matsumoto Y, Yano M \& Kuramochi M (1998) Coronary vasoreactivity to ergonovine after angioplasty: difference between the infarct-related coronary artery and the noninfarct-related coronary artery. Coronary Artery Disease 9, 105-111.

Yildiz O, Smith JR \& Purdy RE (1998) Serotonin and vasoconstrictor synergism. Life Science 62, 1723-1732.

Zieden B, Kaminskas A, Kristenson M, Kucinskiene Z, Vessby B, Olsson AG \& Diczfalusy U (1999) Increased plasma $7 \beta$ hydroxycholesterol concentrations in a population with a high risk for cardiovascular disease. Arteriosclerosis Thrombosis and Vascular Biology 19, 967-971. 